\title{
Matrimonio y herencia en el Antiguo Testamento
}

El Antiguo Testamento narra la historia de grupos dispersos de pastores nómadas, vinculados entre sí por lazos de parentesco y caracterizados por una religión monoteísta que logran un territorio donde asentarse. Éste, a su vez es disputado y compartido con otros pueblos propiciándose los fenómenos de aculturación y sincretismo. Sin embargo, a pesar de la importancia de los cambios en el modo de vida, sus creencias y estructura socio-cultural apenas se ven modificadas o transformadas por las influencias extranjeras.

Con el presente artículo pretendemos mostrar cómo el tipo de familia y las estrategias matrimoniales avaladas y refrendadas por una religión son los principales baluartes de este proceso. No es casual el amplísimo desarrollo que los temas relacionados con la familia y el matrimonio alcanzan en la obra, donde, además de enumerarse y reiterarse, en unos y otros libros, las genealogías de los personajes, se incluyen historias concretas y emblemáticas sobre algunos de ellos que ilustran toda la problemática con sus variantes y alternativas ${ }^{1}$. En ellas, Yahveh interviene constantemente a favor de la rectitud y continuidad del orden social establecido y la pureza y no contaminación del sistema. No se trata de algo gratuito; su propia supervivencia depende, como es lógico, de la cultura que lo sustenta.

Tras el diluvio, las primeras noticias que nos da el Génesis sobre el tipo de vida del pueblo judío, nos dibujan a familias extensas, casas patriarcales que abarcan al padre, las esposas con sus esclavas, las concubinas, los hijos de todas ellas, las hermanas solteras, viudas o repudiadas y los hermanos varones, subordinados al patriarca, con sus correspondientes mujeres e hijos. Todos ellos pastorean en una determinada porción de territorio, hasta que el elevado número de individuos aconseja que los varones que no perpetúan el linaje emigren con sus familias y

1 Todas las citas del Antiguo Testamento están tomadas de José María BovER y Francisco CANTERA Burgos (eds.): Sagrada Biblia. Versión critica sobre los textos bebreo y griego. (Madrid: Biblioteca de Autores Cristianos, La editorial Católica, 1961). Con una frecuencia mayor a la habitual incluimos los textos originales. El modo como se presentan y su forma de expresión, sin duda resultarán más ilustrativas que cualquier intento por mi parte de parafraserar el Antiguo Testamento. 
se establezcan en otro lugar dando origen a una nueva casa patriarcal. Éstas tienen como principal fin su propia supervivencia y la perpetuación del nombre o linaje paterno que, teóricamente se transmite al primogénito masculino al igual que el grueso de los bienes y la subordinación del resto de los hermanos.

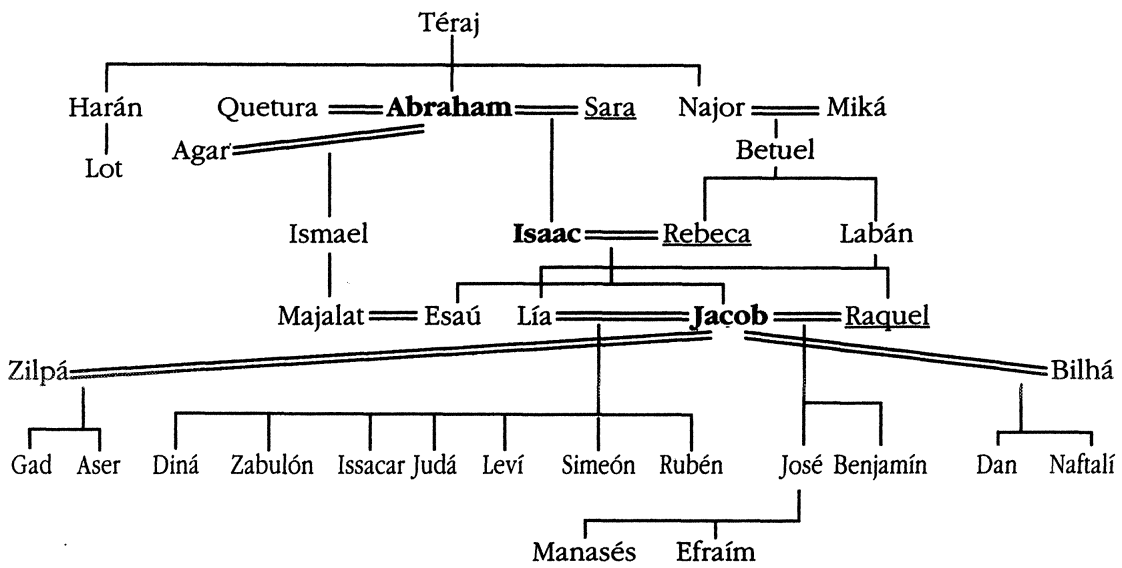

FIG. 1.-Genealogía de los Patriarcas.

\section{LA NORMA ENDOGÁMICA}

Así, el matrimonio ideal no sólo es endogámico y virilocal, sino que, como veremos más abajo, además la esposa preferentemente debe ser seleccionada entre la parentela más próxima por línea paterna, excluyendo los casos considerados como incestuosos. La norma endogámica, sobre todo en lo que afecta al no emparentarse con miembros de países o culturas vecinas, es sin duda el mejor sistema de supervivencia cultural; al evitarse el contacto, se impide el conocimiento de otras alternativas y las posibles desviaciones en las pautas de comportamiento. Yahveh que varias veces se define como un "Dios celoso" sabe bien los peligros de los matrimonios exogámicos, claramente expresados en el Deuteronomio:

Deuteronomio 7,3. No emparentarás con ellas (naciones vecinas y cananeos); no darás tu hija a su hijo ni tomarás para tu hijo a su hija 4 porque apartaría a tu hijo de seguirme y serviría a otros dioses.

Un argumento relacionado también con la aculturación que sin duda haría más mella entre los judíos, se relaciona con la prostitución divina, a 
la que las mujeres seguidoras de Astarté debían someterse al menos una vez en su vida:

Éxodo 34,15. Cuida de no pactar alianza con los moradores del país, porque se prostituyen tras sus dioses, y les ofrecen sacrificios, y se te invitaría y comerías de su sacrificio, 16. y tomarías a sus hijas para tus hijos, y sus hijas se prostituirían tras de sus dioses y harían también prostituirse a tus hijos en pos de los mismos.

El tipo de asentamiento nómada o seminómada, diferente para cada casa patriarcal, dificulta el cumplimiento de esta norma y, en los primeros tiempos implica un desplazamiento a la hora de buscar esposa, como el que tuvo que realizar el criado de Abraham cuando éste decidió casar a su hijo Isaac:

Génesis 24,3 . ...no tomarás mujer para mi hijo de entre las hijas de los cananeos, en medio de los cuales habito, 4. sino que irás a mi tierra y parentela, a fin de tomar mujer para mi hijo Isaac.

Yahveh interviene y el criado va a topar con Rebeca, nieta de Najor, hermano de Abraham; es decir, un matrimonio con la hija del primo, por línea paterna (la avanzada edad a la que parió Sara, obliga al salto de una generación para equilibrar las edades de la pareja). También Jacob se ajusta a la norma y emigra a Paddán Aram para buscar esposa entre las hijas de Labán, hermano de su madre; se trata de matrimonio de primos cruzados por línea materna, (Génesis 28,1-3) ya que, al carecer Isaac, su padre, de hermanos (sólo tuvo hermanastros, hijos de concubinas o esclavas) no es posible realizar el tipo de matrimonio preferente con sus primas, tías o sobrinas por línea paterna.

Sin embargo, el distanciamiento espacial entre los linajes, la inestabilidad del territorio y la cercanía de mujeres extrajeras propician que, a lo largo de todo el Antiguo Testamento, se repitan las violaciones de esta norma, las reprobaciones y castigos divinos por ello y los intentos de rectificación. Uno de los primeros casos es el de Esaú, el hermano mellizo de Jacob, que se había casado con dos hittitas, recibiendo la consiguiente desaprobación y disgusto de sus padres (Génesis 26,43 y 27,46). La poligamia permite a Esaú tratar de contentar a su padre tomando una tercera esposa:

Génesis 28,8. Así pues, observando Esaú que no agradaban las hijas de Canaán a Isaac, su padre, 9. se dirigió a los ismaelitas y, sobre las mujeres que tenía, tomóse por esposa a Majalat, hija de Ismael, el hijo de Abraham, y hermana de Nebayot.

Se trata en este caso de un matrimonio de dos primos paralelos por línea paterna, justo la opción contraria a la adoptada por su hermano 
mellizo Jacob, quien, por otra parte, al desposarse con las dos hijas de Labán había agotado las posibilidades de repetir su estrategia. Sin embargo, Esaú, al que más que el destino, las argucias de su madre y hermano abocaron a la pérdida de la primogenitura, tampoco logró con esta tercera esposa ajustarse verdaderamente a la norma endogámica ya que su nueva esposa, Majalat, efectivamente era nieta de Abraham pero no de su esposa legítima sino de la esclava egipcia Agar, la cual había proporcionado a su hijo Ismael una mujer también egipcia (Génesis 22,20).

Mientras de algunos personajes se nos certifica rápidamente la idoneidad de su matrimonio, como Amram, padre de Aarón y Moisés, casado con su tía Yokébed (Éxodo 6,20), también se repiten las violaciones a la norma endogámica, la mayoría de las veces con sus lógicas consecuencias de aculturación religiosa y castigo divino. El propio Moisés, que nunca pisaría la tierra prometida, se casó con una extranjera:

Números 12,1. María y Aarón murmuraron de Moisés con motivo de la mujer cusita que había tomado, pues habíase desposado con una mujer cusita.

Aunque el caso más grave lo protagonizó el rey Salomón:

1 Reyes 11,1. El rey Salomón amó, además de la hija del Faraón, a muchas mujeres extranjeras, moabitas, ammonitas, idumeas, sidonias e hittitas, de las naciones que había dicho Yahveh a los hijos de Israel: "No os lleguéis a ellas ni ellas se lleguen a vosotros; seguramente inclinarán vuestro corazón tras sus dioses". A ellas se apegó Salomón con amor. 3. ...y sus mujeres pervirtieron su corazón. 4. Pues sucedió que, a la vejez de Salomón, sus mujeres inclinaron a dioses ajenos el corazón real... 5. Salomón rindió pues, culto a Astarté, diosa de los sidonios y a Milkom, abominación de los ammonitas. 6. ... 7. Entonces edificó Salomón, en la montaña que está enfrente de Jerusalen, un bamá a Kemós, abominación de Moab, y a Molok, abominación de los hijos de Ammón. 8. Y lo mismo hizo para todas las mujeres extranjeras, quienes quemaban incienso e inmolaban víctimas a sus dioses.

9. Así pues, Yahveh irritóse con Salomón... 11. ..."Por cuanto se ha dado en ti tal maldad y no has guardado mi alianza y los preceptos que te había ordenado, arrancaré inexorablemente el reino de sobre ti y lo daré a un siervo tuyo. 12. Sin embargo no lo haré en tus días, en atención a tu padre David; de mano de tu hijo lo arrancaré. 13. Sólo que no le quitaré todo el reino, sino que daré una tribu a tu hijo en atención a "David, mi siervo, y a Jerusalén, a la que escogí".

A lo largo del Antiguo Testamento los matrimonios exogámicos se repiten, siendo casi siempre extrajera la mujer. En ocasiones se emprenden drásticas depuraciones.

Esdras 10,2. ..."Hemos prevaricado contra nuestro Dios y hemos tomado mujeres extranjeras de las gentes del país; ahora bien... 3. Concretemos ahora con nuestro Dios un pacto de echar fuera a todas las mujeres extranjeras y los nacidos de ellas... 
14. ...quédense nuestros jefes en representación de la asamblea entera, y cuantos en nuestras ciudades han tomado mujeres extranjeras vengan a plazos señalados, acompañados de los ancianos de cada ciudad y sus jueces, hasta que se haya apartado de nosotros el furor de la cólera de nuestro Dios por este motivo".

También se dan casos en que la mujer extranjera resulta un nuevo miembro en la familia fiel y adecuado ( 1 Rut 4), o que la decisión encierra propósitos belicosos, como la boda de Sansón con una filistea que acabó en matanza durante la propia celebración (1 Reyes 14). Aunque Sansón, desoyendo los consejos de sus padres actuó, al parecer, por inspiración divina, sin duda fue su pertinaz falta de acierto a la hora de fijarse en una u otra mujer, lo que le acarreó la ruina personal.

\section{LA COMPRA DE LA NOVIA}

La obtención de una mujer de otra familia, con el fin de incorporarla a la propia y, gracias a ella, posibilitar la perpetuación del linaje, se acompaña de la donación de una serie de bienes, la dote, que convierte el intercambio o la circulación de mujeres en una compra. El precio de la novia es dado a su padre, o a su hermano mayor que es en caso de orfandad, su responsable, siendo acordado y recibido al concertar el matrimonio, con los esponsales. Sin embargo, una vez consumado, cuando la nueva pareja va a residir a la casa de los padres de él, normalmente a la novia se le restituye o da una parte de ese precio que se ha pagado por ella.

Los conceptos en que se paga este precio, son variables, lo más normal en las sociedades descritas en el Antiguo Testamento es que consistan en plata, tanto en moneda acompañada de ganado o tierras para el padre o el hermano mayor, como en joyas para la madre de la novia y para ésta, a la que también se regalan vestidos y una esclava. Este es el tipo de dote que recibió la familia de Rebeca, cuando el criado de Abraham fue a buscar esposa para Isaac (Génesis, 24,22; 24,47 y 24,52-53). Pero el precio de la novia puede pagarse de formas diversas. Así Jacob, lo pagó trabajando en casa de su suegro Labán:

Génesis 29,18. Como Jacob amase ya a Raquel, contestó:

- Te serviré siete años a cambio de Raquel, tu hija menor.

19. Respondió Labán:

- Mejor es dártela a ti que entregarla yo a otro hombre; quédate conmigo...

21. ..."Pues se ha cumplido mi plazo, dame mi mujer para que me llegue a ella".

22. Y Labán congregó a toda la gente del lugar y celebró un festín; 23. mas por

la noche tomo a su hija Lía y se la llevó [a Jacob], que se llegó a ella. 24. Ade- 
más, Labán diole su propia sierva Zilpá a Lía, su hija, para esclava. 25. A la mañana, hete aquí que era Lía ${ }^{2}$, y dijo [Jacob] a Labán:

-...¿Por qué me has engañado?

26. A lo que contestó Labán:

-No se acostumbra así en nuestro lugar: dar la menor antes de la mayor.

27. Acaba la semana [de bodas] de ésta y te entregaremos también a aquella, por el servicio que me has de prestar todavía durante otros siete años.

28. Hízolo, pues, así Jacob y cumplida la semana de ésta, diole [Labán] a su hija Raquel como esposa. 29. Además Labán entregó su sierva Bilhá, a su hija Raquel en concepto de esclava. 30. El llegóse también a Raquel, a la cual amó más que a Lía, y sirvió aún en casa de Labán otros siete años.

Si en el primer matrimonio, el precio de la novia fue pagado por anticipado, después del engaño, no pudo menos Labán que cobrar el de su segunda hija tras la boda. Sin embargo, la parte de la dote que a ellas correspondía al partir del hogar paterno, cobrada en cabezas de ganado fue fruto de posteriores negociaciones con astucias y engaños entre Labán y Jacob (Génesis 30), haciendo exclamar a Lía y Raquel, cuando Jacob les anuncia la marcha, que hablando con propiedad fue una huida:

Génesis 31,14 ...¿Por ventura tendremos ya parte y herencia en la casa de nuestro padre? 15. ¿No hemos sido estimadas por él cual extranjeras, pues nos ha vendido e incluso se ha comido de lleno nuestro dinero?

Como se ve, poco conforme con la manera en que se estaba realizando el intercambio, Raquel, al marcharse roba a su padre los ídolos familiares, terafim, lo que, al parecer, le daba derecho a participar en la herencia paterna (Gén. 31,19). Al saber de la huida y de la desaparición de los dioses, Labán persigue a Jacob durante siete días, cuando le alcanza registra el campamento en busca de éstos aunque no los encuentra ya que Raquel se había sentado encima de ellos y aduce impureza menstrual para no levantarse delante de su padre. Finalmente suegro y yerno se reconcilian en estas difíciles y complicadas relaciones. Las normas por las cuales dos varones establecen una relación de intercambio - hija-precio novia-parte de dote y herencia que a ella corresponde-, con frecuencia provocan recelos y reticencias entre el suegro y el yerno, en las cuales la mujer toma partido a favor de su marido. Tampoco fueron precisamente buenas las relaciones de Saúl y David, de cuya historia merece destacar la singular dote requerida:

1 Samuel 18, 23. ..." ¿Tan sencillo es a vuestro parecer llegar a ser yerno del rey? Yo soy un hombre pobre y de baja condición.”...

2 La novia durante la ceremonia debe llevar el rostro oculto por el velo, lo que posibilitó el engaño. 
25. ...Decidle a David así: Al rey no le interesa la dote, sino cien prepucios de filisteos para vengarse de los enemigos reales... 26. ...y a David le agradó la condición puesta para llegar a ser yerno del rey. No se había cumplido aún el plazo, 27. cuando David fue y partió con su gente y mató a doscientos filisteos, y llevó sus prepucios que entregó íntegramente al rey para llegar a ser yerno del monarca. 28. Entonces Saúl diole a su hija Mikal por esposa ${ }^{3}$.

En la misma línea de logros militares está la dote requerida por Kaleb, documentándose también en el texto cómo una parte corresponde a la hija que incluso, inducida por su marido logra aumentarla, y el matrimonio preferente con los descendientes del hermano del padre:

Josué 15,16. Y dijo Kaleb: "Quien bata a Quiryat-séfer y la tome le concederé por mujer a mi hija Aksá." 17. Y conquistóla Otniel, hijo de Quenaz, hermano de Kaleb, el cual le dio su hija Aksá por esposa.

18. Y sucedió que, al llegar ella [adonde su marido], él la indujo a pedir a su padre un campo, y como descabalgara del asno díjole Kaleb:

- ¿Qué te pasa?

19. Contestó ella: - Concédeme un favor: puesto que me has dado tierra de secano, dame también tierras de regadío.

Y dióle el regadío superior y el regadío inferior.

La seducción o la violación de una doncella judía, obliga al matrimonio y no sólo no evita la dote sino que endurece las condiciones de la alianza:

Éxodo 22,15 . Cuando un hombre sedujere a una doncella no desposada y yaciere con ella, deberá dotarla para hacerla su esposa. 16. Si el padre de ella rehusare a dársela, pagará el dinero correspondiente a la dote de las doncellas.

Deuteronomio 22,28.-Si un hombre halla a una muchacha virgen que aún no está prometida y la agarra y yace con ella y son sorprendidos, 29. el hombre que ha yacido con ella pagará al padre de la joven cincuenta siclos de plata y quedará por esposa suya, pues la ha desflorado; no podrá repudiarla en toda su vida.

Pero no siempre se llega a un acuerdo sobre la mujer deshonrada y entonces la venganza es la única solución. Esta venganza, normalmente no es ejecutada por el padre, sino por sus hermanos de sangre que, como es bien conocido entre los antropólogos tienen una participación directa en los tratos matrimoniales de sus hermanas y en todo lo concerniente a su parentesco. Ellos son los principales perjudicados ante la deshonra de su hermana que no podrá ser dada en matrimonio a cambio de un buen precio, el cual en gran medida se destinaría a la compra de sus propias esposas. Así, cuando Diná es forzada por Sikem, Jacob, su padre espera

3 Nótese que aunque Saúl sólo pide cien prepucios, David entrega doscientos. 
a que vuelvan los hijos varones del campo antes de tomar ninguna decisión (Génesis 34) . Éstos, al enterarse, regresan inmediatamente, "contristados y encolerizados". El padre de Sikem y él mismo tratan de tomar a Diná para su familia, negociando con sus hermanos y Jacob:

Génesis 34,12. Recargadme mucho donación nupcial y regalo, que yo entregaré cuanto me indiquéis; pero dadme a la muchacha por esposa".

Los hermanos de Diná responden que no pueden entregarla a un hombre que no esté circundado porque para ellos sería un deshonor. Sikem no sólo se circunda sino que convence a todos los varones de la ciudad para que lo hagan, posibilitando los matrimonios mixtos, pero los hermanos de Diná están lejos de perdonar:

Gén. 34,25. Mas sucedió que al tercer día, cuando estaban más aquejados de dolores, dos hijos de Jacob, Simeón y Leví, hermanos de Diná, tomaron sendas espadas y se arrojaron sobre la ciudad a mansalva, matando a todos los varones. 26. También a Jamor y a Sikem, su hijo, mataron a filo de espada, y tomaron a Diná de la casa de Sikem y se salieron. 27. Los hijos de Jacob se lanzaron sobre los muertos y saquearon la ciudad por haber deshonrado a su hermana...

30. Dijo entonces Jacob a Simeón y a Leví:

- Me habéis perturbado, haciéndome odioso a los habitantes del país... y se congregarán contra mí, me desbaratarán y seré exterminado juntamente con mi casa. 31. Mas ellos respondieron:

- Pues qué ¿Habían de tratar a nuestra hermana como a una prostituta?

Como vemos son los hermanos, no los hermanastros ni el padre, quienes se ocupan de vengar el honor de su hermana, incluso contra la voluntad o los intereses generales de la familia. Lo mismo ocurre cuando Ammón, primogénito de David, engaña y fuerza a su hermanastra Tamar, despreciándola posteriormente (al parecer hubiera estado permitido el matrimonio entre hermanastros hijos de rey). La venganza parte de su hermano Absalón, que rumia la afrenta durante dos años, antes de asesinar al primogénito de David. Luego se ve obligado a huir, pero al cabo de tres años podrá regresar, pues su padre ya se había consolado del asesinato de su hijo (2 Samuel 13 y 14).

\section{LA POLIGAMIA}

La poligamia está claramente documentada y legitimada en prácticamente todo el Antiguo Testamento, aunque la primera mención proceda de un miembro de la estirpe maldita de Caín (Lamek casado con Ada y 
Sil.lá, Génesis 4,19). La historia de Abraham resulta ilustrativa: es la propia Sara, su primera y principal esposa quien le da a su esclava Agar. El Génesis además, menciona una segunda esposa Quetura —que no queda muy claro si la tomó antes o después de la muerte de Sara- y, al hablar de la repartición de su herencia, se citan de forma genérica las concubinas. También su hermano Najor tuvo esposa y concubina. Si el heredero de Abraham, Isaac, sólo se unió a Rebeca, los hijos de éste, Esaú y Jacob son claramente poligámicos, Esaú con al menos tres esposas, citadas antes de abandonar la casa paterna y Jacob con dos, más sus respectivas esclavas que también le fueron dadas. Los casos se repiten en el Antiguo Testamento y la poligamia queda legalmente sancionada por varias disposiciones del Deuteronomio $(21,15)$, dándose casos entre los reyes o cabecillas militares verdaderamente notables, como Gedeón que tuvo setenta hijos de sus múltiples mujeres (Jueces, 8,30) o las siete esposas que se le contabilizan a David (2 Samuel, 3,2-5; 3,14-16 y 1 Samuel, 25,42), además de las concubinas y mujeres que tomó en Jerusalén (2 Samuel, 5,13). Aunque sin duda el más escandaloso fue el ya mencionado del rey Salomón que entre esposas y concubinas poseyó a mil mujeres. Su proceder quedó reprobado, aunque de forma genérica, en el Deuteronomio $(17,17)$. No se menciona expresamente en ningún lugar del Antiguo Testamento la prohibición de la poligamia, pero lo cierto es que, para alegría de los comentarista bíblicos, en los últimos libros dejan de parecer casos o éstos se refieren a reyes extranjeros ${ }^{4}$.

\section{LA FAVORITA}

La multiplicación de mujeres conviviendo en una misma casa y compartiendo un sólo varón crea las lógicas rivalidades. La estratificación entre esposas, concubinas y esclavas solo de forma muy leve ayuda a paliar el problema y el propio Yahveh se ve obligado en más de una ocasión, a intervenir en busca del equilibrio y la armonía. La mujer estéril incapaz de perpetuar la descendencia de su esposo es minusvalorada por la fértil:

1 Samuel 1. ...Elqaná... 2. Tenía dos mujeres: el nombre de una era Ana y el de la otra Peninná. Peninná tenía hijos pero Ana carecía de ellos... 4. Llegado el día en que Elqaná ofrecía su sacrificio, acostumbraba a dar a Peninná, su mujer y a todos los hijos e hijas de ella, porciones de la víctima. 5. A Ana empero, daba una sola porción, aunque él amaba a Ana; mas Yahveh había cerrado su seno.

4 Philip and Hanna Goodman, The Jewish Marriage Anthology, Philadelphia, The Jewish Publication Society of America, 1965. 
6. Y su rival la vejaba con vejámenes a fin de humillarla porque Yahveh habíala hecho estéril. 7. Y así se hacía año tras año cada vez que ellas subian a la casa de Yahveh; de esta suerte la vejaba; por lo cual Ana lloraba y no comía. 8. Decíale, pues, Elqaná, su marido: "Ana, ¿por qué lloras, y por qué no comes, y por qué se apesadumbra tu corazón? ¿No valgo yo para ti más que diez hijos?”

Ni siquiera el hecho de que la mujer fértil sea una esclava, entregada al marido por la esposa legal con el fin de paliar su propia esterilidad, resuelve el problema:

Génesis 16,1. Saray, esposa de Abram, no le había dado hijos; mas tenía aquélla una esclava egipcia llamada Agar, 2. y dijo Saray a Abram: "Mira, Yahveh me ha hecho estéril; llégate pues, a mi esclava; quizá obtenga yo hijos por medio de ella"... 3. y Saray, mujer de Abram, tomó a la egipcia Agar, esclava suya, al cabo de diez años de morar Abram en el país de Canaán, y diósela a su marido por esposa. 4. Llegóse él, pues, a Agar, la cual concibió, y viéndose encinta, perdió su señora consideración a sus ojos. 5. Dijo entonces Saray a Abram:

-Recaiga sobre ti la injuria que se me hace. Yo te puse mi esclava en tu regazo y, viéndose encinta, he perdido consideración a sus ojos. Júzguenos Yahveh a mí y a ti.

6. Y contestó Abram a Saray:

-Ahí tienes a tu esclava a tu disposición; haz de ella lo que mejor te parezca. Saray entonces la maltrató, y ella huyó de su presencia. 7. Encontróla, pues, el ángel de Yahveh junto a un manantial de agua, en el desierto cabe la fuente del camino de Sur. 8. Dijo él:

-Agar, esclava de Saray, ¿de dónde vienes y adónde vas?

... 9. ...

- Vuelve a tu señora y humílate a ella.

La intervención divina fue todavía más necesaria en el caso de Raquel y Lía, las dos hermanas casadas con Jacob, cuya rivalidad no cesará hasta la muerte de Raquel, proporcionándole en su disputa sin tregua, hasta doce hijos varones que constituyeron las doce tribus de Israel:

Génesis 29,31. Ahora bien, viendo Yahveh que Lía era menospreciada, hízola fecunda, mientras Raquel quedó estéril. 32. Concibió pues, Lía y dio a luz un hijo, al cual puso por nombre Rubén, pues dijo: "Por cuanto Yahveh ha visto mi aflicción (raá beonyí), ciertamente ahora me amará mi marido" [Hasta cuatro hijos tuvo Lía concedidos por Dios para lograr el amor de Jacob lo cual si mejoró su posición en la familia no eliminó las rivalidades]

Génesis 30,1.-Ahora bien, viendo Raquel que no daba hijos a Jacob, tuvo celos de su hermana y dijo a Jacob:

-Dame hijos, pues si no me muero.

...

3. ...-Ahí tienes a mi esclava Bilhá: llégate a ella para que dé a luz sobre mis rodillas y tenga yo también hijos por medio de ella... 
[La esclava pare dos hijos sucesivos provocando el júbilo de Raquel] 8. Y afirmó Raquel: "Luchas (naftulé) sobrehumanas he reñido (naftalti) con mi hermana y he vencido". Así pues, le denominó Naftalí.

9. Como viese Lía que había cesado de parir, tomó a su esclava Zilpá y diósela a Jacob por esposa. [ésta también le pare dos hijos a Jacob pero la rivalidad no cesa y Lía ayudada por Dios vuelve a parir otros dos varones y una hembra]... 20. Lía dijo entonces: "Me ha regalado Dios un buen regalo: ahora habitará ( $y i$ zbeleni ) conmigo mi marido, pues le he parido seis hijos" y de ahí que le pusiera por nombre Zabulón. 21. Más tarde dio a luz una hija, a la que llamó Diná. 22. Por fin, se acordó Dios de Raquel y escuchóle Dios, dando fecundidad a su seno. 23. Concibió, pues, y dio a luz un hijo. Entonces exclamó: "iHa quitado Dios mi oprobio!". Y le puso por nombre José, diciendo: Añádeme (yosef) Yahveh otro hijo".

...Génesis 35,16. ...dio a luz Raquel y padeció muchas dificultades en su alumbramiento. 17. Sucedió que en medio de las dificultades del parto, dijole la partera: "No temas porque también éste te ha resultado hijo". 18. Ahora bien, al exhalar ella su alma, pues murió, le puso por nombre Ben-oní; pero su padre le llamo Benjamin.

Tiempo después, para evitar situaciones como ésta en que dos mujeres con cercano parentesco disputan a un mismo hombre, en el Levítico se prohiben este tipo de matrimonios poligámicos:

18,17. No descubrirás la desnudez de una mujer y de su hija, ni tomarás la hija de su hijo ni la hija de su hija para descubrir su desnudez; son su carne, sería una infamia.

18,18. No tomarás una mujer junto con su hermana para hacer de ella rival, descubriendo su desnudez además de la de aquélla, mientras viva.

El comentario final "mientras viva" resulta ilustrativo pues el viudo, al casarse con la hermana de la difunta reproduce las mismas circunstancias que aconsejaron su primera unión, lo que hace de este tipo de segundas nupcias, un matrimonio preferente.

Probablemente las luchas entre dos mujeres por logar ser la favorita eran más duras y pasionales que las que se producían dentro de un harén de cuyo funcionamiento nos da cumplida cuenta la historia de Ester (Ester 2), el único caso que hemos documentado en que una mujer judía es dada a un extranjero que además es rey, justificado solamente porque el propósito final es evitar un exterminio del pueblo judío, aunque es significativo que ella sea huérfana y sea su tío quien la entrega.

En un cultura donde la perpetuación del nombre paterno por su descendencia es uno de los valores y las aspiraciones principales, la esterilidad o fecundidad, como ya hemos visto en los casos precedentes son otorgadas por Dios que se vale de esta facultad para contrarrestar las rivalidades de las esposas y castigar impiedades, dejando en ocasiones es- 
tériles o impotentes a todos los miembros de una familia (Génesis 20,17) o población (Macabeos I 1,27). Así la mujer que no concibe debería su estado a un pecado o castigo divino y, cuando el marido no tuviera medios para poseer otra esposa o concubina, estaría abocada al repudio. Sin embargo Yahveh odia el repudio (Malaquias 2,15) y a lo largo de toda la obra se suceden casos en los que mujeres estériles son perdonadas y terminan pariendo, en ocasiones, a edades muy avanzadas, normalmente hijos varones destinados a jugar un papel protagonista en la historia del pueblo judío. Eva debía ser ya bastante mayor cuando parió a Set (Génesis 4,25); centenario era Abraham y nonagenaria Sara, cuando engendraron a Isaac (Génesis 17,17); también la esposa de éste último, Rebeca, necesitó de la intervención divina para paliar su esterilidad y quedarse encinta de mellizos; Raquel, madre de José y Benjamín, empezó a concebir cuando otras mujeres le habían dado ya a su marido al menos once vástagos; ya mencionamos más arriba, la esterilidad de Ana, futura madre de Samuel, y posteriormente de otros tres hijos y dos hijas (1 Samuel 2,18); y lo mismo se dice de la madre de Sansón (Jueces 13). Haciendo una leve incursión en el Nuevo Testamento, igualmente fueron partos tardíos de mujeres estériles, nada menos que el de la madre de San Juan el Evangelista y el de Ana, madre de María, y abuela del propio Jesús. La enseñanza que se debe sacar de todos estos casos es bien clara; no se debe repudiar a una mujer porque no tenga hijos, éstos pueden llegar en cualquier momento e, incluso, probablemente sean elegidos y destinados por Dios a grandes obras en favor del pueblo judío.

\section{LA LEY DEL LEVIRATO}

Làs mujeres que enviudan antes de procrear generan una problemática especial. Se pueden dar casos como el de Judit:

Judit 8,7. ...Su marido Manasés, le había dejado oro y plata, esclavos y esclavas, animales y campos, cuya superintendencia ella tenía.

16,22 . Muchos la codiciaron, mas no conoció varón en todos los días de su vida desde que murió Manasés su marido... 24. ...Antes de morir repartió sus bienes entre los parientes más próximos de Manasés, su marido y entre los de su propio linaje.

Pero esta opción no es la más extendida ya que impide la perpetuación del nombre del marido, uno de los fines supremos y aspiraciones máximas de la sociedad descrita en el Antiguo Testamento. Normalmente la viuda joven rehará su vida y formará una nueva familia gracias a la ley del levirato: 
Deuteronomio 25,5. Cuando unos hermanos vivan juntos y uno de ellos muera sin tener un hijo, la mujer del difunto no habrá de casarse fuera con hombre extraño; su cuñado se llegará a ella y la tomará por esposa y cumplirá con ella la ley del levirato. 6 . El primogénito que ella dé a luz deberá llevar el nombre del hermano difunto, para que su nombre no sea borrado de Israel. 7. Pero si al hombre no le agrada tomar a su cuñada, ésta subirá a la puerta a donde los ancianos, y dirá: "Mi cuñado se niega a perpetuar el nombre de su hermano en Israel; no quiere cumplirme la ley del levirato". 8. Entonces los ancianos de aquella ciudad le llamarán para interpelarle. Si se presenta y dice: "No me agrada desposarme con ella", 9. su cuñada se acercará a él en presencia de los ancianos, le quitará el calzado de su pie y le escupirá a la cara, y, tomando la palabra dirá: "¡Así se hace con el hombre que rehusa edificar la casa de su hermano!" 10. Y se apodará en Israel "Familia del descalzado".

El cumplimiento de esta norma, ante la ausencia de hermanos varones, se traspasa al pariente más próximo por línea paterna: el goel, pero como la propia ley prevee, es fácil que éste no quiera hacerse cargo de una mujer cuya descendencia no computará como propia. La historia de Judá y Tamar se desarrolla en torno al tema:

Génesis 38,6. Más tarde, Judá tomó esposa para Er, su primogénito, la cual se llamaba Tamar. 7. Pero Er, ...fue perverso a los ojos de Yahveh, y éste le quito la vida. 8. Dijo entonces Judá a Onán: "Llégate a la mujer de tu hermano y cásate como cuñado con ella para que suscites a tu hermano descendencia".

9. Más, sabiendo Onán que la sucesión no había de ser suya, cuando se llegaba a la mujer de su hermano, lo malbaraba por tierra para no proporcionar a su hermano descendencia. 10. Y desagradó a Yahveh lo que aquél hiciera, y también le hizo morir. 11. Dijo entonces Judá a Tamar, su nuera: "Mantente viuda en casa de tu padre hasta que sea mayor mi hijo Selá; pues se dijo "No sea que muera también él como sus hermanos"... 12. Pasaron muchos días y murió la hija de Súa, esposa de Judá... 14. Quitóse Tamar inmediatamente de encima los vestidos de su viudez, se cubrió con un velo, se embozó y sentóse a la puerta de Enáyim, en la encrucijada del camino de Tímná; porque había observado que Selá era ya adulto y no había sido dada a él por esposa. 15. Viola, pues, Judá y la creyó una prostituta porque se había cubierto el rostro...

18. Entonces él preguntó:

- ¿Qué prenda te he de dar?

Y contestó:

- Tu sello, tu cordón y el bastón que tienes en la mano.

Dióselo, pues, y se llegó a ella, la cual quedo encinta...

24. Sucedió, pues, que al cabo de unos tres meses avisaron a Judá diciendo:

- Tamar, tu nuera, se ha prostituido e incluso ha quedado encinta de su prostitución.

- ¡Sacadla fuera y sea quemada! —exclamó Judá.

25. Mas, cuando se la sacaba, envió ella recado a su suegro, diciendo: "Del varón a quien estas cosas pertenecen hállome encinta". Y añadió: Comprueba de quién son este sello, este cordón y este bastón". 
26. Reconociólos Judá y dijo:

- Tiene más razón que yo, puesto que yo no la entregué a mi hijo Selá.

Luego ya no volvió más a conocerla.

La historia de Rut y Noemí, nuera y suegra, ambas viudas, tiene un desenlace más feliz: Noemí ve como mueren su marido y sus dos hijos ya casados, antes de tener descendencia. La mujer que se encuentra empobrecida y con dos nueras jóvenes, cuando decide regresar a su pueblo, les recomienda a éstas:

Rut 1,11. ...Volveos, hijas mías, ¿por qué queréis venir conmigo? ¿Tengo yo aún hijos en mis entrañas que puedan llegar a ser vuestros maridos? 12. ...Aunque yo dijere: [Todavía] tengo esperanzas, e incluso esta noche estuviera ya con esposo y hasta diera a luz hijos, 13. ¿acaso los habíais de esperar hasta que fuesen mayores?

Una de las nueras efectivamente vuelve a casa de sus padres, pero Rut, permanece fiel a su suegra y parte con ella a Belén. Allí, ante la falta de recursos, se dedica a espigar ${ }^{5}$ en los campos de Booz, rico pariente de Noemí por parte de la familia de su marido. Booz se conmueve ante la humildad y fidelidad de la joven y le da todo tipo de facilidades. Cuando se lo cuenta a su suegra, ésta replica:

Rut 2,20. ...Ese hombre es pariente cercano nuestro, es uno de nuestros goeles.. 3.3. Lávate, pues y úngete, échate encima tu manto y baja a la era... 4. y cuando él se acueste, nota bien el lugar donde yace; después irás, le destaparás la parte de los pies y te acostarás, y él te indicará lo que debes hacer...

8. Y sucedió que a la media noche el hombre sintió un escalofrío y, volviéndose a mirar, he aquí que una mujer estaba acostada a sus pies $9 . .$.

- Soy Rut, tu sierva - contestóle-. Extiende sobre tu servidora el borde de tu manto, pues tu eres goel. 10. ...

-...Este último acto tuyo de piedad ha sido aún mejor que el primero, al no ir tras de alguno de los jóvenes, ya pobre, ya rico... 12. Ahora bien, aunque en verdad soy goel, existe un goel más próximo que yo. 13. Pasa la noche, y a la mañana, si él quiere ejercer el derecho de goel, bien está, que lo ejerza; mas si no quiere actuar contigo como goel, yo ejerceré el derecho vive Yahveh...

4,1. Por su parte, Booz subió a la puerta de la ciudad, y, sentado allí, he aquí que acertó a pasar el goel de quien había hablado Booz... 3. ...

-Noemí, que ha vuelto de la campiña de Moab, ha puesto en venta la parcela de campo que fue de nuestro pariente Elimélek. 4. He resuelto comunicártelo para decirte: "Adquiérela ante los aquí sentados y en presencia de los ancianos de mi pueblo. Si quieres ejercer el derecho de goel, ejércelo; y si no quieres ejer-

5 Derecho de las viudas y huérfanos que, en gran medida ha persistido hasta nuestros días era marchar detrás de los segadores recogiendo para su provecho, las espigas caídas de las gavillas. 
cerlo, comunícamelo para que yo lo sepa, pues no hay otro goel que tú, y yo detrás de ti... 5. ...

-El día en que adquieras el campo de manos de Noemí, también habrás adquirido a Rut la moabita, mujer del difunto, para que suscites el nombre del muerto sobre su herencia.

6. Entonces dijo el goel:

-[Así] no puedo cumplir como goel, no sea que perjudique mi herencia. Usa tu de mi derecho de goel porque yo no puedo ejercitarlo... 8 . ..

-Adquiérelo para ti -y se descalzó su zapato. 9. Entonces Booz dijo a los ancianos y a todo el pueblo:

- Vosotros sois testigos hoy de que adquiero de manos de Noemí todo lo que fue de Elimélek y cuanto perteneció a Kilyón y Majlón. 10. Además, a Rut la moabita, mujer de Majlón, adquiérola para mí por esposa, a fin de mantener el nombre del difunto sobre su herencia y para que el nombre del muerto no desaparezca de entre sus hermanos y de la puerta de su lugar. Testigos sois de ello hoy...

13. Booz tomó pues a Rut y ella fue su esposa. Luego él llegóse a ella y Yahveh le concedió gravidez y dio a luz un hijo. 14. Entonces las mujeres dijeron a Noemí... 15. El será para ti consuelo del alma y báculo de tu vejez, ya que te lo ha parido tu nuera, que tanto te ama, la cual vale mas para ti que siete hijos." 16 . Y Noemí, tomando al niño, lo puso sobre su regazo y sirvióle de aya.

Como el texto señala con claridad, la esposa es considerada como una pertenencia del marido y corre la misma suerte que el resto de su herencia.

\section{EL REPUDIO}

Aunque se trata de evitar, el repudio de la esposa está documentado y legislado:

Deuteronomio 24,1. Cuando un hombre toma una mujer y se casa con ella, si resulta que ella no encuentra gracia a los ojos de aquél por haberle hallado algún inconveniente, le escribirá un libelo de divorcio, se lo entregará a la mano y la despedirá de su casa. 2. Saldrá, pues, ella del domicilio de él, y podrá ir y casarse con otro hombre. 3. Si este hombre último le cobra aversión, le escribe libelo de repudio, se lo pone en la mano y la despide de su casa, o si muriere el último varón que la tomó por esposa, 4. su primer marido, que la repudió, no podrá volver a tomarla por esposa, después de haberse ella mancillado, porque esto constituiría abominación ante Yahveh. De esta suerte no acarrearás pecado a la tierra que Yahveh, tu Dios, te va a dar en herencia.

Las causas que pueden provocar este repudio están relacionadas en primer lugar con el honor:

Deuteronomio 22,13. Si un hombre casare con una mujer y luego de haberse llegado a ella la cobra aversión, 14. y la imputare acciones difamantes y esparciese sobre ella mala fama y dijere: "Me he casado con esta mujer... y no he encontra- 
do en ella doncellez", 15. entonces el padre de la muchacha y su madre cogerán... 17. ...las pruebas de la virginidad... Y desplegarán la ropa ante los ancianos de la ciudad. 18. Entonces los ancianos de aquella ciudad cogerán al hombre y lo castigarán. 19. Le impondrán una multa de cien siclos de plata, que entregarán al padre de la muchacha, por haber difundido mala fama sobre una doncella de Israel; y quedará por mujer suya, a la cual no podrá repudiar en toda su vida. 20. Pero si el hecho fuera cierto que no se halló doncellez en la muchacha, 21. conducirán a la joven a la puerta de su casa paterna y los hombres de su ciudad la lapidarán con piedras hasta que muera...

La pérdida de la virginidad en doncellas ya desposadas, está considerada como delito femenino si sucede en la ciudad, ya que ella no pidió socorro, castigándose a ambos, hombre y mujer, con la lapidación (Deuteronomio 22,22-24). Pero si la joven es encontrada y forzada en el campo, sólo él violador será merecedor de castigo, puesto que ella aunque gritase no tuvo a quien la socorriese (Deuteronomio 22,25-27).

El sistema para comprobar si están justificados los celos de un hombre, descrito en Números 5,11-31, deja en manos de Dios el castigo: El marido atacado de "celotipía", se presentará ante el sacerdote con una ofrenda —oblación de celos-, el sacerdote hará beber a la inculpada, agua santa mezclada con polvo del tabernáculo y un papel desleído en el que se describe su falta; sí ella es culpable, le acarreará una maldición hinchándose su vientre y enflaqueciendo sus caderas (quedando estéril), pero si es inocente, el brebaje no le hará daño y tendrá descendencia.

No fue sin embargo éste el procedimiento aplicado a Susana (Daniel, 13) a la que dos viejos tratan de forzar; cuando ella pide socorro, la acusan de haberla sorprendido con un joven. Llevado el caso ante la asamblea del pueblo, se da crédito al testimonio de los dos ancianos, frente al de ella, condenándola a muerte. Pero Dios, inspira a Daniel e interviene a su favor:

Daniel 13,48. ...¿ ¿Sin haber examinado el asunto y sin haber puesto en claro la verdad, condenasteis a una hija de Israel?

Se vuelve así a examinar el caso y se interroga a los dos ancianos por separado, que incurren en contradicciones, siendo finalmente ellos los condenados a muerte.

\section{EL ELEGIDO}

Mayor importancia que las rivalidades entre las diversas esposas tienen las que se producen entre hermanos y hermanastros. Está en juego la perpe- 
tuación del linaje paterno, la bendición y la herencia. Teóricamente los derechos son del primogénito varón que acapara los tres conceptos en su persona, quedando para el resto de los hermanos donaciones menores. Pero las historias concretas plasmadas en el Antiguo Testamento violan constantemente esta norma según las circunstancias concretas de cada familia - preferencia del padre o la madre por alguno de los hijos, faltas o violaciones a las normas, fratricidios, ausencia de hijos varones, intrigas de las diversas madres y por supuesto, los designios o los intereses de Dios-.

Ya con los primeros hermanos de la historia, Caín y Abel, se desata la lucha. Caín, agricultor fue el primogénito (Génesis 4,1), pero es el propio Yahveh quien toma partido por su hermano menor, Abel, que se dedica al pastoreo y cuyos sacrificios le agradan mientras reprueba los de su hermano mayor. Parece que el único pecado de Caín era su medio de subsistencia y el desagrado de Dios señala un primer sistema socio-económico para el pueblo escogido, diferente al de las poblaciones agrícolas del Próximo Oriente, profesadoras de cultos idolátricos. Los celos y el resentimiento provocan el primer asesinato de la historia y la aparición de una casta o linaje maldito. El posterior nacimiento de un tercer hijo, Set tiene como fin suplir al asesinado Abel, al que en ningún caso podrá suplantar Caín, el primogénito desterrado y maldito (Génesis 4,25).

Si con el diluvio universal se pretende extirpar el mal de la tierra, el germen de éste, con enfrentamientos y desigualdades entre hermanos se encuentra dentro del propio arca, entre los hijos de Noé: Sem, Cam y Jafet. Noé, agricultor con viñedos, se emborracha un día y queda desnudo en medio de su tienda, Cam, del que expresamente se nos dice que era el menor (Génesis 9,24), falta al respeto a su padre contemplado su desnudez e invitando a sus dos hermanos Sem y Jafet a hacer lo mismo, proposición que rechazan. La reacción de Noé, maldiciendo a Canaán, el hijo de Cam, y bendiciendo a Sem y a Jafet, inicia otra de las tradiciones en las familias del Antiguo Testamento: las bendiciones y maldiciones paternas, suponiendo, la primera opción, la supremacía del hijo bendito sobre sus hermanos que serán sus siervos o esclavos y asociada a la primogenitura, la perpetuación del linaje y la posesión de la herencia. En el relato vemos también cómo el castigo o la maldición no se aplica al infractor sino a sus hijos o descendientes, al igual que ocurrió en el caso de Salomón, antes citado; el honor o la reputación del padre (Noé o David) hubiera quedado mancillado con el de sus hijos. Así son sus respectivos descendientes o linajes los que reciben la maldición lo que sin duda debía ser el mayor motivo de deshonra para el varón del Antiguo Testamento.

El Génesis no aclara cual fue el primero de los hijos de Téraj (Gen. 11,26: Téraj llevaba de vida setenta años cuando engendró a Abram, a 
Najor y a Harán), y si seguimos textualmente la cita, tal vez procedieran de distintas esposas ya que es imposible que una sola mujer pariera a los tres en un mismo año. El proceder de Abram abandonando la casa paterna por indicación de su padre parece mostrar que se trataba de uno de los segundones. La primogenitura recayó en Najor, el único varón que permaneció junto a su padre, ya que el otro hermano, Harán, había muerto en vida del patriarca, mientras que su hijo, Lot marchó con Abram (Gén. 11,26-32). Las prácticas de poligamia y adopción hacen poco probable que la esterilidad de Saray, la mujer de Abram provocara la pérdida de la primogenitura a su esposo, al ver Téraj que por esta línea no se podría perpetuar su hombre. Así, Yahveh nuevamente seleccionaría a un segundón para fundar el linaje del pueblo escogido (Gén. 12,1-3).

Las rivalidades entre hermanos se complican al tomar partido sus madres por unos u otros. Nuevamente Sara, la primera esposa de Abraham defiende los intereses de su hijo Isaac, frente al primogénito Ismael:

Génesis 21,9. Y como viese Sara que el hijo que Agar la egipcia había parido a Abraham embromaba a su bijo Isaac, 10. indicó a Abraham: "Expulsa a esa esclava y a su hijo, porque no debe heredar el hijo de esa esclava con mi hijo Isaac". 11. La proposición pareció muy mal a los ojos de Abraham en razón de su hijo. 12. Pero Dios dijo a Abraham: "No te desagrade todo lo que afirma Sara respecto del muchacho y de tu esclava; escucha sus palabras, pues es en Isaac en quien será reputada la descendencia; 13 . aunque también del hijo de la esclava haré un pueblo por ser prole tuya".

14. Levantóse, pues, Abraham muy de mañana, tomó pan y un odre de agua, lo dio a Agar, cargándolo sobre el hombro de ésta, así como al muchacho y la despidió.

Como en la historia anterior, se apunta aquí, otra faceta de la familia, conviene que el padre antes de morir designe al que perpetuará su nombre y los demás hermanos salgan del hogar; consecuentemente despidió también al resto de sus hijos:

Génesis 25,5. Mas Abraham dio todo lo que poseía a Isaac; 6. en cuanto a los hijos de las concubinas que Abraham tuvo, otorgóles donaciones y, viviendo él todavía, los despidió de junto a su hijo Isaac, hacia el este, a la tierra de oriente.

Pero la lucha por la primogenitura y las rivalidades entre hermanos llegan a su paroxismo entre los mellizos Esaú y Jacob, hijos de Isaac y Rebeca, quienes comenzaron su enfrentamiento dentro del propio seno materno:

Génesis 25,22. Mas los niños se entrechocaban en su seno... 23. Díjole Yahveh: "Dos pueblos hay en tu vientre, / y dos naciones se separarán de tus entrañas, // y una nación prevalecerá sobre la otra, / y la mayor servirá a la menor". 
La primogenitura correspondía a Esaú, el primero en salir ${ }^{6}$, aunque el otro agarrado a su talón, le siguió de forma inmediata. Los padres se dividen en sus preferencias y mientras Isaac prefiere a Esaú, Rebeca se inclina por Jacob (Gén. 25,28). La historia de su rivalidad nos muestra cómo, no sólo prevalece el menor, sobre el mayor, sino también el deseo de la esposa, sobre el del padre y cabeza de familia. Lo mismo había ocurrido cuando Sara expulsó a Ismael. Además, en ambas historias, las esposas están sancionadas por Dios ${ }^{7}$. En una primera fase, Jacob compra a su hermano la primogenitura a cambio de un guiso de lentejas, aprovechando que éste volvía desfallecido del campo (Gén. 25,29-34). El siguiente paso, para que esta venta no pudiera ser reversible consiste en robarle la bendición paterna (Gén. 27): Inducido por su madre y valiéndose de que Isaac estaba ciego, cuando éste requiere a Esaú para bendecirle antes de morir, se hace pasar por él recibiéndola en su lugar:

Génesis 27,34. Cuando Esaú oyó las palabras de su padre lanzó un grito fuerte y en extremo amargo, y dijo a su padre:

-Bendíceme también a mí, padre mío.

35. Mas respondió:

- Ha venido tu hermano con astucia y se ha cogido tu bendición.

36. Dijo entonces Esaú:

- Con razón se le puso por nombre Jacob, pues ésta es la segunda vez que me engaña (yaqebeni): cogióse mi primogenitura, y he aquí que ahora se ha cogido mi bendición.

Y añadió:

- ¿Acaso no has reservado bendición para mî?

37. Replicó Isaac, diciendo a Esaú:

- He aquí que le he constituido señor respecto a ti, le he entregado a todos sus hermanos por siervos y de cereales y mosto le he asegurado; ¿qué puedo, pues, hacer por ti, hijo mío?

... 41. En adelante, Esaú aborreció a Jacob... "Pronto vendrán los días de duelo por mi padre y mataré a mi hermano Jacob". 42. Como se le anunciaran a Rebeca los proyectos de Esaú, su hijo mayor, envió llamar a Jacob, su hijo pequeño, y díjole: "Mira, tu hermano Esaú proyecta vengarse de ti, matándote. 43. ...Anda

6 En caso de hermanos mellizos, la partera debía tener buen cuidado de poner algún tipo de marca al que saliera primero para que no pudiera confundirse con su hermano. Así nos los confirma el Génesis 38,27 al relatarnos el doble parto de Tamar en el que también debieron darse disputas dentro del seno ya que aunque sacó antes la mano uno de los mellizos, finalmente fue el otro, el primero en nacer.

7 En realidad tanto en este caso como en otros ejemplos -elección de Abraham por Dios para fundar el pueblo elegido y adopción y bendición por Jacob de los dos hijos de José-, se representa simbólicamente, a nivel del parentesco, el destino del pueblo judío: Un pueblo menor en lucha por un territorio con culturas o civilizaciones más poderosas, logra prevalecer sobre ellas. 
escápate hacia Labán, mi hermano, en Jarán, 44. y mora con él algún tiempo hasta que se pase la furia de tu hermano, 45 . hasta que desaparezca la cólera fraterna para contigo y olvide lo que le has hecho. Yo enviaré a sacarte de allí. ¿Por qué he de quedar privada de vosotros dos en un solo día?" ${ }^{8}$.

Veinte años después (Gén. 33), Jacob regresa con sus esposas, esclavas, la abundante descendencia arriba citada, y numerosos rebaños. A pesar del tiempo transcurrido, teme la reacción de Esaú, al que envía presentes. Cuando le ve acercarse acompañado de cuatrocientos hombres, piensa en un ataque; la forma como prepara a sus mujeres e hijos habla por si misma de la estratificación de sus afectos y preferencias:

Génesis 33,1. ...Entonces repartió los hijos en torno a Lía y Raquel y en torno a las dos siervas. 2. Y puso a las siervas y sus hijos en cabeza, detrás a Lía y sus hijos, y a Raquel y José los postreros.

Mas Esaú que también ha enriquecido y formado una familia busca la reconciliación y acepta los regalos de su hermano; cada uno ha formado su linaje pero finalmente será Jacob el que quede en tierra paterna:

Génesis 36,6. Luego cogió Esaú a sus mujeres, sus hijos y sus hijas y todas las personas de su casa, sus rebaños, todas sus bestias y toda la fortuna que había adquirido en tierra cananea, y marcho al país de Seir, lejos de la presencia de Jacob, su hermano; 7. porque la hacienda de ambos era harto abundante para morar juntos, y la tierra de su hospedaje no era capaz de sustentarlos a causa de la ganadería de los mismos.

La abundante prole de Jacob también se disputará la primogenitura o, hablando con propiedad convertirse en el elegido para perpetuar el nombre paterno. En ese caso los signos de predilección por uno de ellos provoca la reacción en conjunto de los restantes:

Génesis 37,3. Ahora bien, Israel [Jacob] amaba a José más que a todos sus hijos, por haberlo tenido en la vejez, y habíale hecho una túnica de varios colores.

4. Vieron, pues, sus hermanos que su padre le amaba con preferencia a todos sus hijos y cobráronle tal odio, que no podían hablarle pacíficamente.

No ayudan a solucionar las cosas los sueños de José que se deben interpretar como su supremacía ante sus hermanos y éstos deciden matarle. Finalmente piensan que es mejor venderle por veinte siclos de plata a unos ismaelitas que se lo llevan a Egipto.

8 Después de asesinar a su hermano, Esaú se hubiera visto obligado a huir con lo cual efectivamente Raquel perdería a sus dos hijos. 
Cuando Jacob ve próxima su muerte, después de que él y el resto de sus descendientes se trasladaran también a Egipto, para lograr sobrevivir en los años de carestía que Dios envió, da una bendición específica a cada uno de sus doce hijos y designando cual sería su sucesor (Gén. 49). No resulta difícil imaginar que la primogenitura que correspondía a Rubén, primer hijo parido por Lía, va a ser nuevamente alterada en favor de José, el primogénito de Raquel, la esposa favorita. El pretexto o la justificación de este proceder, se encuentra en la grave falta que cometió Rubén al tomar a Bilhá, la esclava que Rebeca había proporcionado a su esposo (Gen. 35,22 y I Crónicas 5,1). Aunque tal acción es considerada como incestuosa conviene recordar que, en realidad, entre la esclava y Rubén no había ningún vínculo de sangre.

Gén. 49,3. RUBÉN, tú eres mi primogénito; / mi fuerza y primicia de mi virilidad; cumbre de dignidad y cumbre de poder.

4. Hirviente como el agua, no gozarás primacía, / porque subiste al lecho de tu padre, lo profanaste entonces: ¡mi tálamo escaló!...

22. José es retoño de tocón fructífero, / retoño de tocón fructífero cabe una fuente, cuyos vástagos sobrepasan el muro.

23. Dieron en hostigarle lanzando tiros, / le han atacado los saeteros;

24. mas su arco perseveró pujante / y han continuado ágiles sus brazos y sus manos, por la virtud del Fuerte de Jacob, / por el nombre del Pastor y Roca de Israel.

25. Por el Dios de tu padre, El te auxilie; / por Dios Omnipotente, El te bendiga: bendiciones del cielo por arriba, / bendiciones del Abismo recostado abajo, bendiciones de los pechos y el seno;

26. Las bendiciones de tu padre han sobrepujado / las bendiciones de los montes antañones, las riquezas de los collados eternos, / en la cabeza de José recaigan, en la testa del príncipe de sus hermanos.

Jacob lleva más allá sus bendiciones y adopta a los dos hijos mayores de José, pero, al bendecirlos, también altera el orden ${ }^{9}$, sin duda su propia experiencia personal, debió pesar en su ánimo:

Gén. 48,5. Ahora bien, tus dos hijos que te han nacido en el país egipcio antes de mi llegada a Egipto a donde ti, sean como míos, Efraím y Manasés serán para mí como Rubén y Simeón; 6 en cambio, la descendencia tuya engendrada después de ellos será para ti; con el nombre de sus hermanos serán denominados en su posesión...

12. Entonces José los sacó de entre las rodillas de Jacob y se prosternó rostro en tierra. 13. Luego tomó José a los dos, a Efraím a su derecha, o sea la izquierda de Israel, y a Manasés a su izquierda, o sea la derecha de Israel, y los acercó a

9 El texto también nos informa del ritual de adopción consistente en colocar entre las rodillas al muchacho. 
éste. 14. Israel entonces extendió su diestra y púsola sobre la cabeza de Efraím, que era el pequeño, y su izquierda sobre la cabeza de Manasés, cruzando así sus manos, aunque Manasés era el primogénito. 15. Y bendijo a los hijos de José... 17. Mas, como observase José que su padre ponía su mano derecha sobre la cabeza de Efraím, parecióle mal y, tomando la mano de su padre para trasladarla de la cabeza de Efraím a la cabeza de Manasés, 18. dijo José a su padre:

-Así no padre mío, pues éste es el primogénito; coloca tu mano sobre su cabeza. 19. Pero sus padre se negó, diciendo:

-Lo sé, hijo mío, lo sé; también éste llegará a formar un pueblo y también él será grande; pero no obstante, su hermano menor será mayor que él y su posteridad formará una multitud de pueblos. 20. ...y antepuso Efraím a Manasés.

21. Dijo después Israel a José:

- He aquí que yo voy a morir; mas Dios estará con vosotros y os restituirá al país de vuestros padres. 22. Yo te mejoro entre tus hermanos con una ladera que conquisté de los amorreos mediante mi espada y mi arco.

Primogenitura y mejora en la herencia, son conceptos asociados. El proceder de Jacob primando al hijo de Rebeca queda legalmente reprobado en el Deuteronomio:

Deuteronomio 21,15 . Cuando un hombre tenga dos mujeres, la una amada, ta otra aborrecida, y ambas le parieren hijos y fuera el hijo primogénito de la aborrecida, 16. resultará que el día de dejar en herencia a sus hijos lo que poseyere, no podrá considerar primogénito al hijo de la amada frente al primogénito de la aborrecida, 17. sino que ha de reconocer como primogénito a éste, entregándole doble porción de todo cuanto posea, pues es la primicia de su vigor y tiene derecho de primogenitura.

En historias posteriores se dan casos perfectamente ajustados:

2 Crónicas 21,2. ...todos éstos eran hijos de Josafat, rey de Juda. 3. Su padre habíales dado abundantes regalos en plata, oro y cosas preciosas, juntamente con plazas fortificadas en Judá; pero el reino habíaselo concedió a Joram, pues era el primogénito.

pero también, con frecuencia, se viola la norma teórica en favor de los sentimientos o las consideraciones personales. Así, entre los múltiples hijos y esposas de David, será Salomón quién le suceda en el reinado; se trata del segundo hijo de Betsabee, la esposa de Urías, a la que no sólo deseó y amó, hasta cometer adulterio, sino que, además propició la muerte de su esposo. En este caso, Dios castigó a David matando al primer hijo, fruto del pecado (2 Samuel 12,14-25), pero Salomón, el segundo, concebido ya dentro del matrimonio queda eximido ("Yahveh le amo" $-2 \mathrm{Sa}$ muel 12,24-) y podrá heredar. Los hijos fruto del adulterio quedan malditos (Sabiduría 3,16 y 4,1-6) y condenados a no perpetuar su nombre, 
asimismo los ilegítimos no heredan y deben salir de la casa paterna, como le sucedió a Jefté:

Jueces 11,1. Ahora bien, Jefté, el galaadita, era un guerrero valiente, aunque hijo de prostituta; y había engendrado Galaad a Jefté. 2 . La esposa de éste habíale dado hijos, y cuando crecieron los hijos de la mujer expulsaron a Jefté y le dijeron: "No has de heredar en la casa de nuestro padre, porque eres hijo de otra mujer".

Tampoco la norma de que la herencia corresponda sólo a los varones se aplica siempre, sobre todo si el padre al morir deja a hijas solteras en su casa que no han recibido su parte de la dote en el momento de la boda:

Job 42,13. Además tuvo catorce hijos y tres hijas... 15. No se hallaban en todo el país mujeres tan hermosas como las hijas de Job, y su padre les dio parte en la herencia entre sus hermanos.

Transmisión del nombre paterno, herencia y primogenitura en sociedades de tipo patriarcal, necesitan soluciones especiales en casos de descendencia exclusivamente femenina y naturalmente el Antiguo Testamento se ocupa de ello:

Números 27,1. ...las hijas de Selofjad... 2. Presentáronse pues, ante Moisés, ante el sacerdote Elazar y ante los príncipes y toda la comunidad a la entrada de la tienda de reunión, diciendo: 3. "Nuestro padre murió en el desierto, pero él no intervino en la facción de los que se conjuraron contra Yahveh, en el bando de Coré, sino que murió por su pecado, y no tuvo hijos. 4. ¿Por qué el nombre de nuestro padre ha de ser excluido de en medio de su familia debido a no haber tenido hijo? Dadnos propiedad territorial entre los hermanos de nuestro padre". 5. Moisés presentó la causa de ellas ante Yahveh 6. y Este respondió a Moisés, diciendo: 7. "Dicen bien las hijas de Selofjad; dales, desde luego, propiedad hereditaria entre los hermanos de su padre y transmíteles la herencia de éste. 8. Y a los hijos de Israel hablarás en estos términos: Cuando un hombre muera sin tener hijo, traspasaréis la herencia a su hija; 9. y si no tiene hija, daréis su herencia a sus hermanos. 10. Si no tuviere hermanos, la daréis a los hermanos de su padre; 11. y si su padre careciere de hermanos, daréis su herencia a su pariente más próximo dentro de su familia, el cual la poseerá.

Rápidamente, los príncipes de las casas paternas se dieron cuenta del problema que esta decisión podía provocar:

Números 36,2. ..."Yahveh mando a mi señor que repartiera a los israelitas por sorteo el país en concepto de heredad. Asimismo, a mi señor le fue ordenado por Yahveh diera a sus hijas la heredad de Selofjad, nuestro hermano. 3. Mas si 
ellas se casan con alguien de [otra] tribu israelita, su patrimonio se sustraerá al de nuestros padres e irá a acrecer la herencia de la tribu de aquellos con quienes se casan, sustrayéndose así del lote de nuestra herencia... 6 . He aquí puntualmente lo que ha ordenado Yahveh respecto a las hijas de Selofjad: se casarán con quien les plazca, con tal que lo hagan dentro de una familia de su tribu paterna, 7. para que la herencia de los de Israel no pase de una tribu a otra, sino que los israelitas han de retener cada uno la heredad de su tribu paterna... 9. ...por cuanto las tribus de los hijos de Israel han de estar vinculadas cada una a su herencia"... 10. ...así hicieron las hijas de Selofjad, 11. y Majlá, Tirsá, Joglá, Milká y Noá, hijas de Selofjad, casáronse con hijos de sus tíos. 12. Casáronse pues, dentro de las familias de los hijos de Manasés, hijo de José, y la heredad de ellas quedó en la tribu de la familia de su padre.

Aunque en relatos anteriores, los matrimonios con parientes muy próximos, primos o tíos, eran mayoritarios, hasta ahora no se había expresado tan claramente su conveniencia en relación con la no dispersión de las tierras y su reagrupamiento dentro de un sólo linaje. La norma endogámica es más estrecha en lo que a mujeres se refiere como es lógico en una sociedad patriarcal con residencia virilocal.

El matrimonio con la rica heredera que corresponde al pariente más próximo por línea paterna, no es siempre es una buena opción. El varón que después de pagar una dote adquiere una mujer, dispone libremente de ella y la incorpora a su familia o funda un linaje propio, pero con las herederas, ellas deben perpetuar el suyo y además, si no son huérfanas tendrán que atender a sus padres durante la vejez; el hombre deberá cambiar su residencia y su linaje por el de ella. La sorprendente historia de Tobías, resuelve muchos de estos problemas: Tobit y Ana habían empobrecido hasta el punto de mandar a su único hijo a cobrar una antigua deuda contraída por Gabaelo (Tobit 4 y 5). Ana al verle marchar, sin saber que el ángel Rafael era su compañero de viaje, no puede menos que angustiarse:

Tobit 5,18. Se puso a llorar Ana, su madre, y dijo a Tobit; ¿Por qué enviaste a nuestro hijo? ¿No es el báculo de nuestra mano, entrando y saliendo en nuestra presencia? 19. Dinero y más dinero... No haya tal, antes váyase al traste a trueque de nuestro hijo.

Cuando el ángel y Tobías llegan a la Medina, cerca de Ecbátana, después de haberse provisto del corazón, el hígado y la hiel de un pez que les saltó junto al Tigris (los dos primeros por sus cualidades como ahuyentadores de demonios y el tercero para curar la ceguera producida por cataratas a Tobías), Rafael sugiere:

Tobit 6,11. ...Conviene que] hoy pernoctemos en casa de Ragüel. El es pariente tuyo, y tiene una hija única por nombre Sara. 12. Hablaré sobre ella para que te 
sea dada por mujer, pues a ti corresponde su herencia, y tu eres el único de su linaje.

Los reparos de Tobías, a la proposición son contundentes:

Tobit 6,14. Entonces el muchacho dijo al ángel: Hermano Azarías, he oído decir que la muchacha ha sido dada a siete maridos, y que todos en el tálamo perecieron [la misma noche. $\mathrm{Y}$ decían que un demonio los mataba]. 15. $\mathrm{Y}$ ahora yo soy único para mi padre, y me temo que en entrando muera como los primeros; porque le tiene afición un demonio que a ella no la daña sino que, si uno quiere llegarse a ella, a éste mata. Y ahora temo no [sea que yo muera y precipite la vida de mis padres a su sepulcro con la pena que] tendrán de mí; y otro hijo no les queda que los sepulte. 16. Díjole el ángel: ¿No te acuerdas de lo que te mandó tu padre sobre que tomases mujer de la casa de tu padre... 17. ...Mas tú, cuando la tomes por esposa, entrando en el tálamo, durante tres días te abstendrás de llegarte a ella, y no harás otra cosa que darte con ella a la oración. ...Y la misma noche tomarás del rescoldo de los perfumes y pondrás encima parte del corazón y del hígado del pez y harás humo, y lo olerá el demonio, y huirá, y no volverá por los siglos de los siglos.

Los padres de Sara escuchan la propuesta de matrimonio y a pesar del miedo que les causan las siete muertes anteriores redactan el documento matrimonial y le dan su hija a Tobías, esa misma noche (aunque discretamente Ragüel manda a un criado que excave una tumba antes del amanecer por si muriera, enterrarle sin que se haga público). Tobías cumple los preceptos del ángel y no muere; los padres de Sara no caben de júbilo y celebran una boda de catorce días, el doble de lo habitual, tratando de retener a la pareja en su hogar, mientras Tobías pugna por marcharse sabedor de la inquietud que acecha a sus propios padres. En el momento de la separación Sara cobra ya una parte de su herencia y recibe las recomendaciones de su padre:

Tobit 10,10. Levantándose Ragüel, le entregó a Sara, su mujer y la mitad de sus haberes: siervos y siervas, bueyes y ovejas, asnos y camellos, [vestidos], plata [y ajuar]... [Ve] a tus suegros, hónralos; ahora son ellos tus padres.

La pareja marcha cargada de bienes, incluida la deuda de Gabaelo que el ángel Rafael había ido a cobrar. La boda se vuelve a celebrar durante otros siete días en la casa de Tobit. Tobías y Sara permanecen con los padres de él, en Nínive, hasta sus muertes, pero tras éstas y por recomendación del propio Tobit, parten a la Medina, a casa de los padres de ella:

Tobit 14,12 ...Y se marcho Tobías con su mujer y sus hijos y los hijos de sus hijos y volvió a sus suegros, y los halló sanos en buena vejez. [Y habitó en Ecbátana con] Ragüel su suegro. 13. Y cuido respetuosamente de sus suegros en su vejez, 
y les cerró los ojos y los sepultó honrosamente y heredó la hacienda [de Ragüel] y la de Tobit, su padre.

La no dispersión de la herencia fuera del linaje está cuidadosamente reglamentada y las ventas, incluidas las de la propia persona como esclavo, deben hacerse al pariente más próximo por línea paterna. De no ser así, éste tiene derecho al rescate de la propiedad ${ }^{10}$ :

Levítico 25,25 . Si tu hermano empobreciera y vendiere de su propiedad, su pariente más próximo vendrá y retraerá la venta hecha por su familiar. 26. Si alguno no tuviere rescatador, mas llegare a encontrar medios suficientes para su retracto, 27. tendrá en cuenta los años transcurridos desde su venta e indemnizará el valor restante al individuo a quien la había vendido, tornando así aquella a su propiedad. 28. Pero si no halla medios bastantes para indemnizarle, lo vendido quedará en poder del comprador hasta el año jubilar, y en el jubileo saldrá libre y volverá a posesión del vendedor.

Levítico 25,47. Si un advenedizo o forastero que vive contigo hiciere fortuna junto a ti y, en cambio, tu hermano empobreciere junto a él y se vendiere al advenedizo que contigo reside, o a descendiente de familia de advenedizo, 48. [el nacionall poseerá, después que se hubiere vendido, derecho al rescate; uno de su hermanos podrá rescatarle. 49. o lo rescatará su tío o un hijo de su tío, o bien uno de sus parientes próximos dentro de su familia, o si se hiciere con medios, él mismo se podrá rescatar.

Los intentos de sustraer a un hombre la herencia de sus padres son castigados por Yahveh, como en el caso de Ajab que, ante la negativa de Nabot a venderle una viña heredada, induce a su lapidación, provocando la cólera y el castigo divino:

1 Reyes 21,19 ....En el mismo sitio donde han lamido los perros la sangre de Nabot, te han de lamer los perros la sangre también a ti.

Los modelos de familia, matrimonios y sistemas hereditarios, descritos en el Antiguo Testamento son fácilmente reconocibles en las sociedades actuales del mundo Mediterráneo ${ }^{11}$ : Desde la designación, entre los hijos,

10 Un caso práctico de la compra de terrenos por el pariente más próximo es relatado en Jeremías 32,8-12. También en 2 Samuel 9 se cuenta como David restituye a Mefibóset las heredades de su abuelo Saúl.

11 John DAVIS, Antropología de las sociedades mediterráneas (Barcelona: Ed. Anagrama, 1983); Patrocinio GARCía BARRIUSO, Derecho Matrimonial Islámico y Matrimonios de Musulmanes en Marruecos (Madrid: Instituto de Estudios Africanos. CSIC, 1952); Raphael PATAI, Francis Lee UtLEY and Dov NOY (Eds), Studies in Biblical and Jewish Folklore (Bloomington: Indiana University Press, 1960); John G. PERISTIANY, Mediterranean Family Structures (Cambridge: Cambridge University Press, 1973); John G. PERIS- 
de un heredero que perpetúe el linaje, reciba la totalidad o una mejora en la herencia y asista a los padres durante su vejez, hasta la adopción en caso de esterilidad, el matrimonio con la viuda del hermano, la endogamia, el matrimonio preferente con primas y tías del linaje paterno, pasando por la compra de la novia y las soluciones adoptadas en caso de descendencia exclusivamente femenina. Conflamos en que la selección de textos que no agota la problemática quedando muchos temas sin tocar ayude a conocer mejor las raíces del teórico sistema de parentesco y las soluciones prácticas o las estrategias adoptadas según unas circunstancias siempre variables.

\author{
MATILDE FERNÁNDEZ MONTES \\ Departamento de Antropología \\ Instituto de Filología. CSIC
}

El Antiguo Testamento narra la historia de grupos dispersos de pastores nómadas, vinculados entre sí por lazos de parentesco y caracterizados por una religión monoteísta que logran un territorio donde asentarse. Éste, a su vez, es disputado y compartido con otros pueblos propiciándose los fenómenos de aculturación y sincretismo. Sin embargo a pesar de la importancia de los cambios en el modo de vida, sus creencias y estructura socio-cultural apenas se ven modificadas o transformadas por las influencias extranjeras. Con el presente artículo pretendemos mostrar cómo el tipo de familia y las estrategias matrimoniales avaladas y refrendadas por una religión son los principales baluartes de este proceso.

The Old Testament tells the story of several groups of nomadic pastoralists -connected among themselves by kin ties, and all of them having a monotheistic religion- who arrive in a territory where they settle. This territory, however, is both disputed by, and shared among, other peoples, and this situation breeds aculturation and sincretism. Nevertheless, despite the ensuing changes in livelihood, the pastoralists' beliefs and sociocultural structure were barely altered or transformed by the foreign influences. In the present paper I intend to show how the family type and the marriage strategies, both underwritten and sanctioned by the monotheistic religion, were the key factors of the resilience of those beliefs and the socio-cultural structure.

TIANY (Coomp.), Dote y matrimonio en los paises mediterráneos (Madrid: Centro de Investigaciones Sociológicas / Siglo XXI, 1987); Julian PITT-RIVERS (Ed.), Mediterranean countrymen. Essays in the Social Anthropology of the Mediterranean (Paris-La Haye: Mouton \& Co., 1963); Julian PITT-RIvERS, Honor y gracia, 1966; Julian PITT-RIVERS y J. G. PERISTIANY (Eds.), Honor y Gracia (Madrid: Alianza Universidad, 1992); J. PRAT, "La mujer en el oriente bíblico y en Cataluña", Etbnica, 10 (1975); Joaquín RODRíGUEZ LÓPEZ, El desorden de las cosas. Matrimonio familia y berencia en la Sierra Norte de Madrid (Inédito); Joaquín RODRíGUEZ LÓPEZ, "Las razones del desaliento", Economía y Sociedad. Revista de Estudios Regionales de la Comunidad de Madrid, 10 (1994), pp. 181-200. 